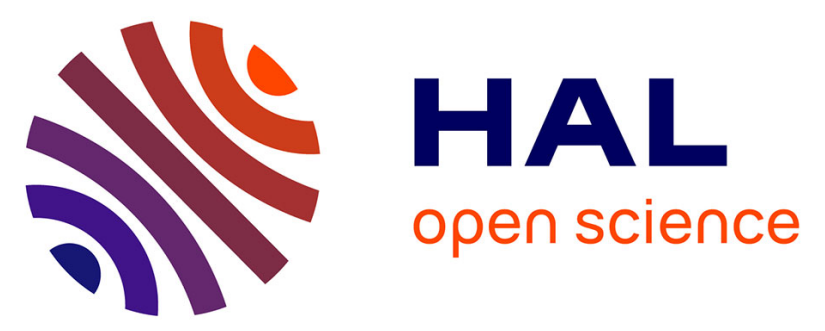

\title{
High Yield synthesis of aspect ratio controlled graphenic materials from anthracite coal in supercritical fluids
}

Suchithra Padmajan Sasikala, Lucile Henry, Gulen Yesilbag Tonga, Kai Huang, Riddha Das, Baptiste Giroire, Samuel Marre, Vincent M. Rotello, Alain Penicaud, Philippe Poulin, et al.

\section{To cite this version:}

Suchithra Padmajan Sasikala, Lucile Henry, Gulen Yesilbag Tonga, Kai Huang, Riddha Das, et al.. High Yield synthesis of aspect ratio controlled graphenic materials from anthracite coal in supercritical fluids. ACS Nano, 2016, 10 (5), pp.5293-5303. 10.1021/acsnano.6b01298 . hal-01323318

\author{
HAL Id: hal-01323318 \\ https://hal.science/hal-01323318
}

Submitted on 17 Jun 2021

HAL is a multi-disciplinary open access archive for the deposit and dissemination of scientific research documents, whether they are published or not. The documents may come from teaching and research institutions in France or abroad, or from public or private research centers.
L'archive ouverte pluridisciplinaire HAL, est destinée au dépôt et à la diffusion de documents scientifiques de niveau recherche, publiés ou non, émanant des établissements d'enseignement et de recherche français ou étrangers, des laboratoires publics ou privés. 


\title{
High yield synthesis of aspect ratio controlled graphenic materials from anthracite coal in supercritical fluids
}

Suchithra Padmajan Sasikala ${ }^{\dagger}$, Lucile Henry ${ }^{\dagger}$, Gulen Yesilbag Tonga ${ }^{\ddagger}$, Kai Huang ${ }^{\S}$, Riddha Das ${ }^{\ddagger}$, Baptiste Giroire $^{\dagger}$, Samuel Marre ${ }^{\dagger}$, Vincent M. Rotello ${ }^{\ddagger}$, Alain Penicaud ${ }^{\S}$, Philippe Poulin ${ }^{*}$, and Cyril Aymonier ${ }^{* \dagger}$

+ CNRS, University of Bordeaux, ICMCB, UPR 9048, Pessac 33600, France

¥ Department of Chemistry, University of Massachusetts, Amherst, Massachusetts 01003, United States

$\S$ Centre de Recherche Paul Pascal, CNRS, University of Bordeaux, Pessac 33600, France

\begin{abstract}
This paper rationalizes the green and scalable synthesis of graphenic materials of different aspect ratios using anthracite coal as a single source material under different supercritical environments. Single layer, monodisperse graphene oxide quantum dots (GQDs) are obtained at high yield (55 wt \%) from anthracite coal in supercritical water. The obtained GQDs are $\sim 3 \mathrm{~nm}$ in lateral size and display a high fluorescence quantum yield of $28 \%$. They show high cell viability and are readily used for imaging cancer cells. In an analogous experiment, high aspect ratio graphenic materials with ribbon-like

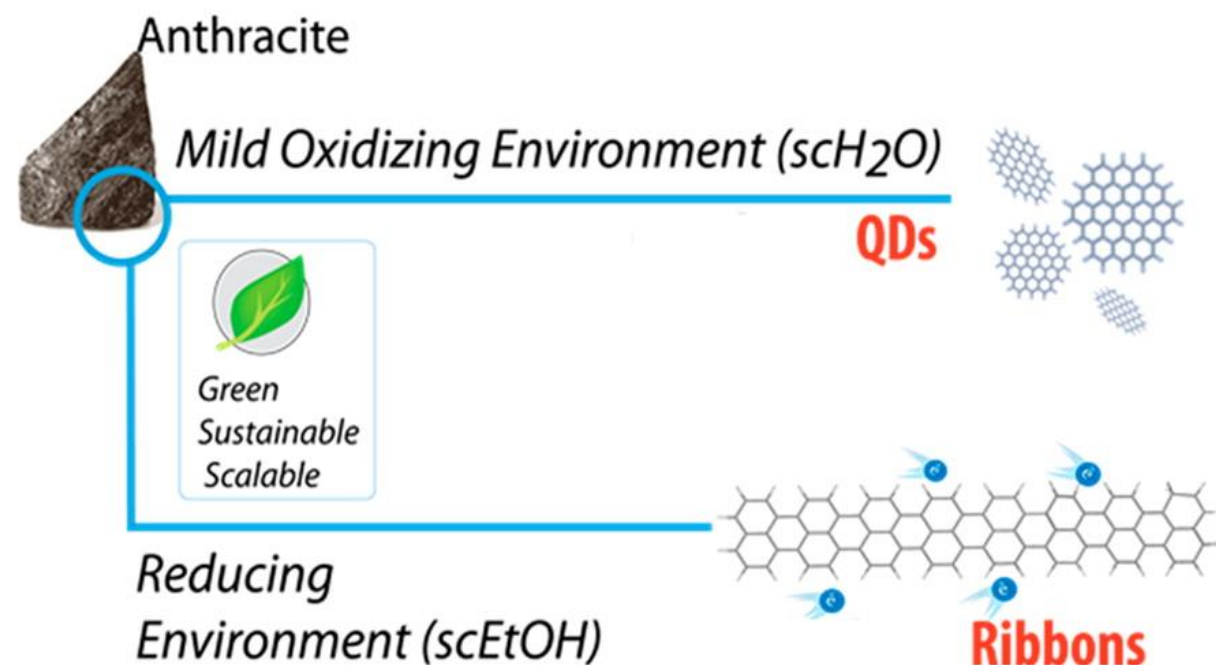
morphology (GRs) are synthesized from the same source material in supercritical ethanol at a yield of $6.4 \mathrm{wt} \%$. A thin film of GRs with $68 \%$ transparency shows a surface resistance of $9.3 \mathrm{k} \Omega / \mathrm{sq}$. This is apparently the demonstration of anthracite coal as a source for electrically conductive graphenic materials.

Graphene has been hailed as the miracle material of the 21 st century since its in-depth study in 2004 by Novoselov et al.(1) Because of its unusual combination of unique properties and technological impact, considerable progress has been achieved recently in the processing of graphene and its associated nanostructures, including graphene based quantum dots and ribbons. This has opened many exciting applications for these materials in optoelectronics, sensing, nanoelectromechanics, thermoelectric devices, and bioimaging, among many others. (2, 3) Adhering to the recommended nomenclature for two-dimensional carbon materials,(4) in this article by referring to GQDs and GRs, we mean graphene oxide/reduced graphene oxide quantum dots and ribbons, 
respectively. GQDs are generally synthesized through solution-based methods such as electrochemical, hydrothermal, acidic oxidation, microwave, and organic synthesis.(5-14) The limiting factors for these existing processes are long treatment times $(24-48 \mathrm{~h}$ ), need for preoxidation steps, and tedious post synthesis purification procedures. In most of the cases, the obtained GQDs have broad size distribution, and have limitations on the product purity as well as the quantum yield. GRs, on the other hand, are usually obtained through Chemical Vapor Deposition (CVD) processes, lithographic patterning, sonochemical cutting of graphene, unzipping of carbon nanotubes, and organic synthesis. Only the CVD process has been proven to be scalable for low defect GRs, which however faces difficulties in removing GRs from the surface of metal catalysts.(15-19) In general, classical chemical methods for synthesis of graphenic materials are time-consuming and based on the use of harsh reactants, metal catalysts or ultrasonication.(20) In this scenario, either a scalable and practical production method for graphenic structures with good opical/electrical properties or an identification of cheap sources other than graphite is challenging. If successful, this would advance the industrial applications of graphenic materials even more rapidly.

Coal is a cheap energy source that contains graphitic crystalline domains linked by amorphous carbon chains (Figure S1, Supporting Information). It has been reported that most of the weakest bonds in coal structure can be broken/destroyed by depolymerization reactions including oxidation, pyrolysis, and cationic depolymerization.(21) There have been numerous attempts to degrade the aliphatic portion of coal, while keeping the aromatic structure intact through oxidation, which however often results in degradation of both aliphatic and aromatic domains.(22) Very recently, in a pioneering work, Ye et al. $(23,24)$ reported an oxidation method that comprises ultrasonication and heat treatment of coal in a nitrating mixture at $120{ }^{\circ} \mathrm{C}$ for $24 \mathrm{~h}$, followed by dialysis (for 5 days) and cross-flow ultrafiltration procedures to produce GQDs. Similarly, Zhang et al.(25) also isolated GQDs by refluxing coal in $\mathrm{HNO}_{3}$ for $24 \mathrm{~h}$, followed by a series of centrifugation, sedimentation, redispersion, and neutralization procedures. In addition to the need for harsh reaction conditions and long post treatment purification procedures, the acid oxidation methods presented by the two groups for coal derived GQDs suffer from low product yield(23) and low quantum yield ( $2 \%$ with quinine sulfate as reference).(25) The development of a scalable method using milder reaction conditions and yet providing different graphene based products with good yield and high quality is desirable to make coal an input for graphenic materials. Coal has an inherent disordered structure compared to graphite, and is thus easier to exfoliate. Selective depolymerization in a controlled atmosphere offered by supercritical fluids could be an appropriate method to have access to graphitic domain without inducing many defects. In this work, we have demonstrated that an oxidizing supercritical fluid (supercritical water, $T_{\mathrm{c}}=374{ }^{\circ} \mathrm{C}$ and $P_{\mathrm{c}}=22.1 \mathrm{MPa}$ ) treatment can extract highly emissive single layer GQDs from coal within $120 \mathrm{~min}$. On the other hand, a reducing supercritical fluid (supercritical ethanol, $T_{\mathrm{c}}=240.9^{\circ} \mathrm{C}$, and $P_{\mathrm{c}}=6.1 \mathrm{MPa}$ ) treatment results in electrically conductive GRs within 60 min. Our methodology does not require any preoxidation or post-treatment purification procedures and is scalable for mass production in an environmentally benign way. While this study puts forward a more effective and green alternative process for deriving GQDs from coal with enhanced product yield and product quality compared to existing literature, this 
is the first report on deriving electrically conductive graphenic structures from coal which is confined only as an energy source until date.

\section{Results and Discussion}

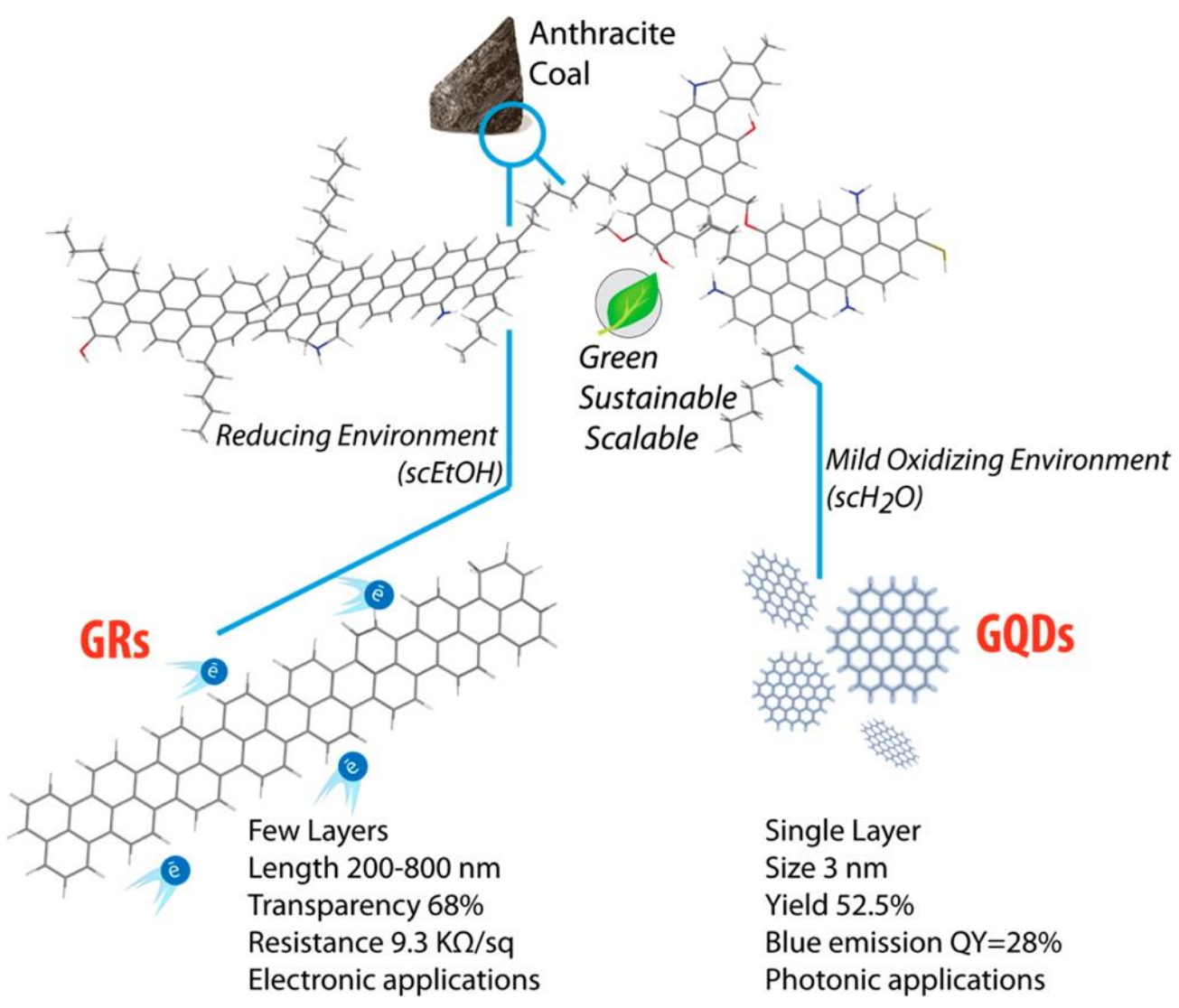

Scheme 1. Schematic of GQDs and GRs Derivation from Anthracite Using Supercritical Fluids as Swelling and Oxidizing/Reducing Media

Scheme 1 represents the concept of this work showing that controlled oxidation and reduction of anthracite coal lead to selective extraction of highly emissive and electrically conductive graphenic structures, respectively. In this study, anthracite was selected over other coal types due to its lower impurity and high carbon content $(>75 \%) .(22)$ The molecular structure and detailed characterization of anthracite coal used in this study is given in Supporting Information (Figures S1, S2, S3a). Large carbon flakes of heterogeneous size distribution (0.5-8 $\mu \mathrm{m})$ with crystalline and amorphous domains were observable in high-resolution transmission electron microscopy (HRTEM). The Raman spectrum showed characteristic graphitic D band at $1375.3 \mathrm{~cm}^{-1}$ and $\mathrm{G}$ band at $1607.5 \mathrm{~cm}^{-1}$. The $\mathrm{x}$-ray photoelectron spectroscopy (XPS) survey showed strong signals of $\mathrm{C} 1 \mathrm{~s}(\sim 76 \%), \mathrm{O} 1 \mathrm{~s}$ $(\sim 11 \%), \mathrm{N} 1 \mathrm{~s}(\sim 9 \%)$, and $\mathrm{Na} 1 \mathrm{~s}(\sim 4 \%)$ (Other impurity elements such as $\mathrm{Cl}, \mathrm{Se}$, and $\mathrm{F}$ were also seen in trace amount which were disregarded in quantitative elemental analysis). The attenuated total reflectance Fourier transform infrared spectroscopy (FTIR-ATR) spectrum showed the presence of aromatic H-Csp ${ }^{2}$ (698 and 3055 $\left.\mathrm{cm}^{-1}\right)$, alkoxy $\mathrm{C}-\mathrm{O}\left(1063 \mathrm{~cm}^{-1}\right)$, in ring aromatic $\mathrm{C}-\mathrm{C}$ stretch $\left(1586 \mathrm{~cm}^{-1}\right), \mathrm{C}=\mathrm{C}$ stretch $\left(1619 \mathrm{~cm}^{-1}\right)$, and $\mathrm{O}-\mathrm{H}$ $\left(3391 \mathrm{~cm}^{-1}\right)$ vibrations. As a reference experiment, firstly we ultrasonicated anthracite in water and ethanol for 60 min each. The analysis of the resulting products showed that ultrasonication has led to the formation of small 
flakes of a few hundred nanometers in size (Figure S3b) with properties similar to that of the starting material. The obtained flakes did not exhibit any observable photoluminescence under excitation with a UV lamp (365 $\mathrm{nm})$. In contrast, supercritical water $\left(\mathrm{scH}_{2} \mathrm{O}\right)$ treatment of anthracite coal at $T=400{ }^{\circ} \mathrm{C}$ and $P=25 \mathrm{MPa}$ for a contact time of 60 min resulted in highly photoluminescent GQDs-1. They were found to be stable in water and of lateral size distribution of 4.0-6.0 nm (Figure 1a,b).
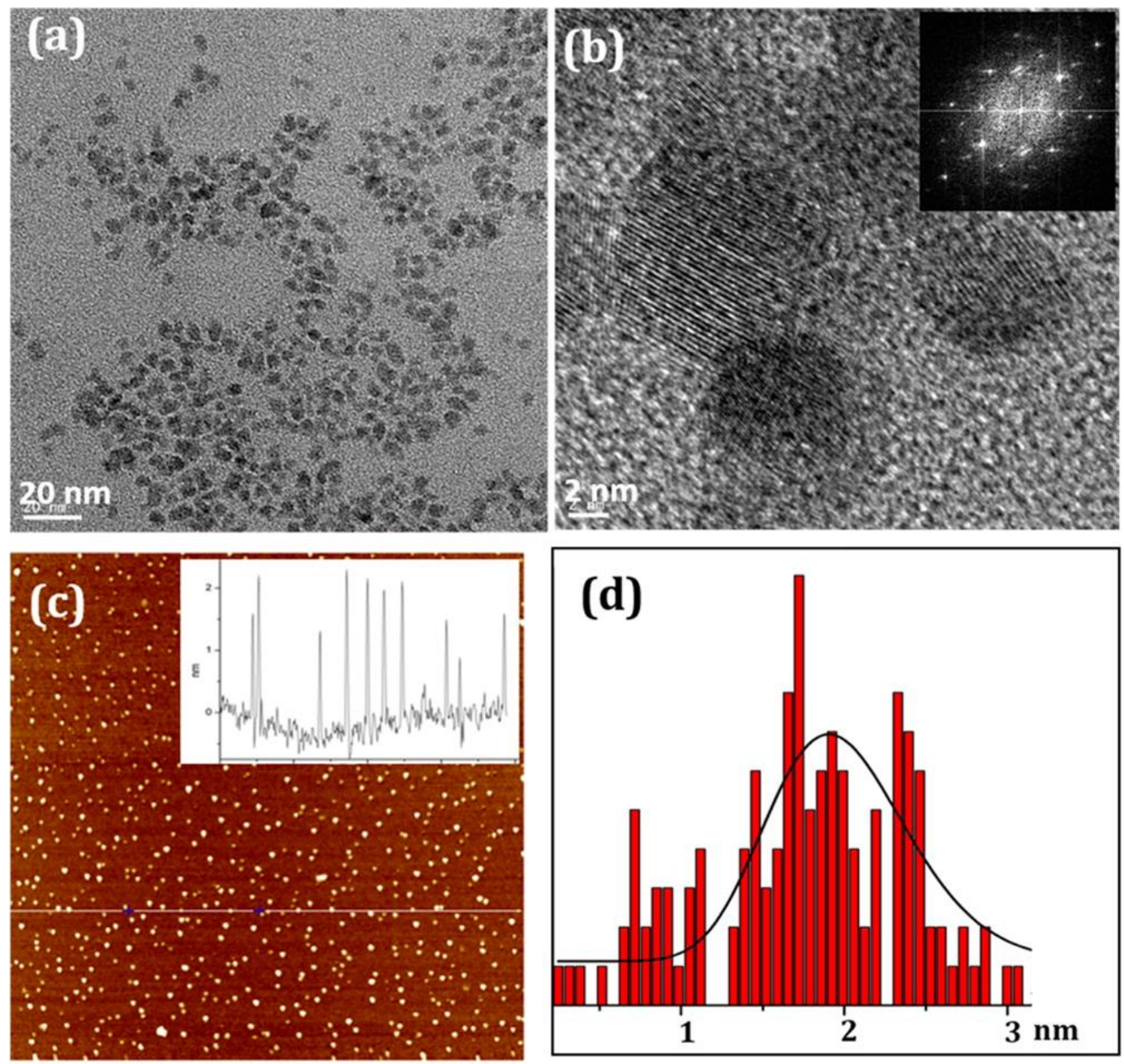

Figure 1. (a) HRTEM image of GQDs-1 obtained by supercritical water treatment for 60 min. (b) A magnified HRTEM image displaying graphene fringes. Inset is FFT pattern indicating that the GQDs-1 are crystalline with a lattice spacing of $0.24 \pm 03 \mathrm{~nm}$ corresponding to hexagonal graphene lattice fringes. (c) AFM image of GQDs deposited on a mica surface and inset is its height profile along the line drawn. (d) The thickness distribution of the GQDs-1 in panel c, indicating that the particle thickness is in the range of $0.5-3 \mathrm{~nm}$.

Most of the particles exhibited $<3.0 \mathrm{~nm}$ thickness corresponding to six to seven graphene layers (Figure 1c,d). Increasing the contact time of $\mathrm{scH}_{2} \mathrm{O}$ with anthracite to 120 min resulted in GQDs-2, displaying a narrow size distribution of $2.6 \pm 0.4 \mathrm{~nm}$ (Figure $2 \mathrm{a}$ ) in diameter. The HRTEM of single GQDs-2 particle showed hexagonal unit cell in honeycomb network. The live fast Fourier transform (FFT) image (inset in Figure 2b) showed six spots arranged in a hexagonal pattern with a spacing of $0.21 \mathrm{~nm}$ corresponding to the (100) plane of graphene. The average thickness determined by AFM (Figure 2c) was $0.4 \pm 0.2 \mathrm{~nm}$ corresponding to single layer graphene. $(4,7,23)$ 

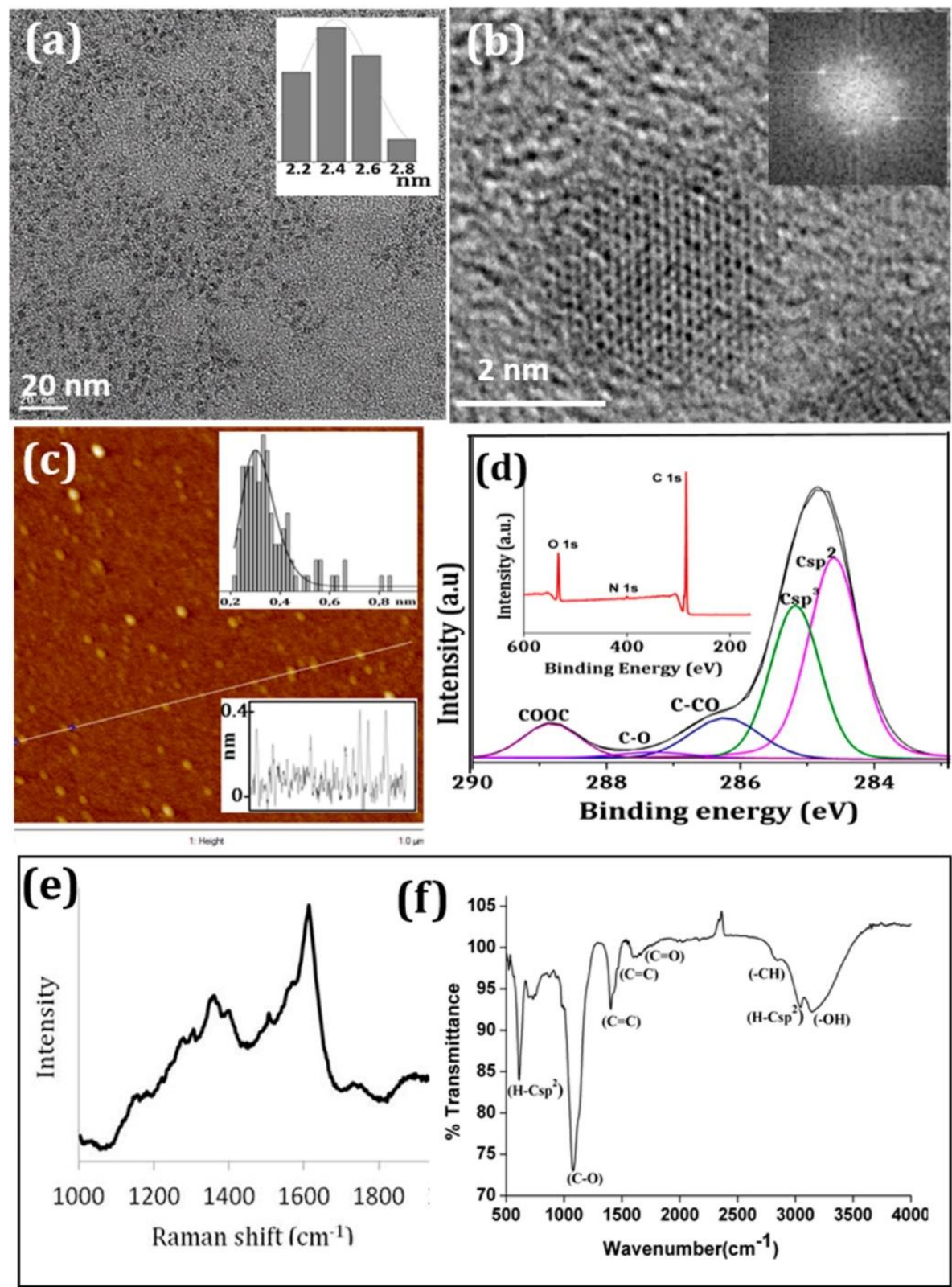

Figure 2. Characterization of GQDs-2: (a) TEM image displaying homogeneous distribution of particles and inset is the size distribution profile. (b) HRTEM image of one GQDs-2 particle displaying the arrangement of carbon atom in a hexagonal manner. Inset is FFT pattern. (c) AFM image of GQDs-2 deposited on a mica surface and insets are height distribution and height profile taken along the white line inserted in the image. (d) High-resolution C 1s-XPS spectrum, XPS survey is inset. (e) surface enhanced Raman spectrum of GQDs-2 deposited on Ag covered SERS substrate under excitation of $638 \mathrm{~nm}$. (f) FTIR-ATR spectrum of GQDs-2, obtained after evaporation of water.

Figure $\mathrm{S} 4$ unravels the $\mathrm{scH}_{2} \mathrm{O}$ cutting process of anthracite as a function of time from 10 to $120 \mathrm{~min}$. It is interesting to observe that the direct cutting down of large anthracite flakes started as early as 10 min (Figure $\mathrm{S} 4 \mathrm{a})$. However, we could not find any obvious lattice fringes in these quasi-spherical particles ( $\sim 150 \mathrm{~nm})$. Upon the progress of $\mathrm{scH}_{2} \mathrm{O}$ treatment to $30 \mathrm{~min}$, the thickness of carbon spheres decreased significantly. One could clearly observe an arrangement of carbon nanoparticles within each carbon sphere (Figure S4b). The HRTEM image displayed distinguishable graphene lattice fringes with $0.21 \mathrm{~nm}$ spacing of nanoparticles which seem to be arranged in random directions within large spheres (of lateral size 115-140 nm). However, domains without any 
distinguishable fringes could also be seen. Increasing the treatment time to 60 and 120 min resulted in a homogeneous dispersion of few layered GQDs-1 and single layered GQDs-2, respectively (Figure S4c,d). Both GQDs-1 and GQDs-2 displayed crystalline nature (inset of Figure S4c,d). The total product yield achieved after 60 and 120 min of $\mathrm{scH}_{2} \mathrm{O}$ treatment is 63.0 and 54.5\%, respectively, which are to the best of our knowledge, the highest yield for crystalline GQDs reported so far with a top down approach. The light gray and yellow tinted suspension containing GQDs-1 and GQDs-2, respectively, in water were found to be completely stable. The GQDs-1 and GQDs-2 could be recovered by evaporation of water, and could be redissolved in other polar solvents such as ethanol, tetrahydrofuran (THF), and dimethylformamide (DMF). However, the as-obtained GQDs-1 in water suspension displayed slight sedimentation after one month, whereas GQDs-2 displayed good stability for months. Hence, we investigated further GQDs-2, which are single layer GQDs. We assume that on the course of time, the oxidative behavior of $\mathrm{scH}_{2} \mathrm{O}$ may have introduced more oxygenated functional groups on the GQDs-2 which may have helped them to be stable in water. The dielectric constant of water drops from 78.5 (at $25^{\circ} \mathrm{C}$ ) to 6.0 at critical point $\left(374{ }^{\circ} \mathrm{C}, 22.1 \mathrm{MPa}\right.$ ) due to the reduced number of hydrogen bonds. At this point, $\mathrm{scH}_{2} \mathrm{O}$ behaves like a nonpolar solvent and induces cleavage of chemical bonds especially the ether and carboncarbon (C-C) bonds.(26-28) It has been reported that parallel hydrolysis and pyrolysis reactions can occur in $\mathrm{scH}_{2} \mathrm{O}$ with molecules containing a saturated carbon attached to a heteroatom containing leaving group.(29) One main conclusion from our understanding about $\mathrm{scH}_{2} \mathrm{O}$ is that the high reactivity of $\mathrm{scH}_{2} \mathrm{O}$ and the concomitant hydropyrolysis reaction may have led to the depolymerization of coal through $\mathrm{C}-\mathrm{C}$ bond fission in the carbon lattice. Yet, the $\mathrm{scH}_{2} \mathrm{O}$ oxidation appears to be selective and brings about minimum aromatic ring degradation as opposed to the commonly used oxidizing agents, which are drastic and result in degradation of both aromatic and aliphatic components in the coal.(22) In addition, exfoliation effect of $\mathrm{scH}_{2} \mathrm{O}(30)$ is confirmed by our results which showed significant reduction in number of layers for the obtained GQDs with an increase of the $\mathrm{scH}_{2} \mathrm{O}$ treatment time (Figure S4). Given that there was no observable sedimentation in the product after $\mathrm{scH}_{2} \mathrm{O}$ treatment of anthracite, we can assume that the amorphous fractions of anthracite were decomposed and only crystalline domains remained intact. This has also been previously reported that the polycyclic compounds with heteroatoms are decomposed to gaseous products such as $\mathrm{CO}_{2}, \mathrm{~N}_{2}, \mathrm{~N}_{2} \mathrm{O}$ during $\mathrm{scH}_{2} \mathrm{O}$ treatment.(31) The XPS analysis (Figure 2d) of GQDs-2 showed no traces of impurity elements compared to initial anthracite precursor (as shown in Figure S2e). The oxidation effect of $\mathrm{scH}_{2} \mathrm{O}$ was evident as XPS displayed strong signals of $\mathrm{C} 1 \mathrm{~s}(85.9 \%)$ and $\mathrm{O}$ 1s (14.1\%), which included fractions of $\mathrm{Csp}^{2}(284.4 \mathrm{eV}), \mathrm{Csp}^{3}(285.2 \mathrm{eV}), \mathrm{C}-\mathrm{CO}(286.1 \mathrm{eV}), \mathrm{C}-\mathrm{O}(287.1 \mathrm{eV})$, and COOC $(288.8 \mathrm{eV})$ peaks. The $\mathrm{COOH}$ contribution $(289.8 \mathrm{eV})$ and $\mathrm{N} 1 \mathrm{~s}(399.8 \mathrm{eV})$ signals were negligible. Due to the nanosize of GQDs-2, we have studied Surface Enhanced Raman spectrum on a substrate covered by Ag particles, which advocated the presence of graphitic domains (Figure 2e). The ordered $\mathrm{G}$ band was more pronounced than disordered $\mathrm{D}$ band with an $I_{\mathrm{D}} / I_{\mathrm{G}}$ ratio of 0.321 , which was consistent with the above-mentioned HRTEM images and SAED patterns. The FTIR-ATR spectrum of GQDs-2 (Figure 2f) displayed strong epoxy (C-O-C) groups at $1058 \mathrm{~cm}^{-1}$, weak carbonyl groups $(\mathrm{C}=\mathrm{O})$ at $1720 \mathrm{~cm}^{-1}$, and broadened -OH group at 3371 $\mathrm{cm}^{-1}$. We can assume that more epoxy chains and minimum hydroxyl functional groups exist in the GQDs-2, as a result of limited oxidation effect of $\mathrm{scH}_{2} \mathrm{O}$. 
The absorption and photoluminescence (PL) measurements were carried out with diluted aqueous solution of GQDs at a concentration of $0.2 \mathrm{mg} / \mathrm{mL}$. The absorption spectrum of GQDs-2 showed a prominent absorption peak at $227 \mathrm{~nm}$ due to the $\pi-\pi^{*}$ transition of $\mathrm{C}=\mathrm{C}$ and other shoulder peaks at 271 and $320 \mathrm{~nm}$ due to $\mathrm{n}-\pi^{*}$ transition within one or several functional groups such as $\mathrm{O}-\mathrm{C}=\mathrm{O}, \mathrm{C}=\mathrm{O}$, and $\mathrm{C}-\mathrm{OH}$ (Figure $3 \mathrm{a}$ ). The $\mathrm{pH}$ of the as-synthesized GQDs-2 suspension was slightly alkaline ( $\mathrm{pH}$ 8.2). Decreasing the $\mathrm{pH}$ to acidic condition ( $\mathrm{pH}$ 2.5) did not alter the absorption maxima. However, a slight red shift of absorption peak from 271 to $287 \mathrm{~nm}$ was observed for alkaline conditions at $\mathrm{pH}$ 13.0. The respective PL-Excitation (PLE) spectrum corresponding to emission at $440 \mathrm{~nm}$ showed distinct excitation bands at 261, 304, 386, and $404 \mathrm{~nm}$ irrespective of the $\mathrm{pH}$ of the GQDs-2 suspension (Figure 3b). The corresponding PL spectra were found to be stable in all the $\mathrm{pH}$ window from 2.5 to 13.0, with an excitation independent peak maxima (Figure 3c-e), unlike many chemically derived GQDs-2, for which the emissive centers are free zigzag edge sites.(7, 23, 32-35) Such free zigzag sites (or $-\mathrm{COOH}$ functionalized edges) under acidic conditions get protonated and a complex between the zigzag sites and $\mathrm{H}^{+}$is formed, making the emissive state inactive in PL. $(7,33)$ The stable and high PL intensity of GQDs-2 at $\mathrm{pH} 2.5$ and 8.2 indicated that the free zigzag edge sites were not responsible for the observed PL. However, PL peak maximum was red-shifted at strong alkaline conditions $(\mathrm{pH}=13.0)$, indicating the lowering of the band gap with a slight decrease of the PL intensity compared to that at $\mathrm{pH} 2.5$ and 8.2. The red-shift in alkaline water can be attributed to negatively charged surface due to deprotonation of surface hydroxyl/carboxyl groups. They inhibit the aggregation of the particles. The observed slightly lower PL intensity may have resulted from a slower radiative pathway at higher emission wavelength.(34) Also, we noted that the PL spectra of GQDs-2 at pH 2.5 and 8.2 split into two strong sharp peaks of comparable intensities at 416 and $440 \mathrm{~nm}$, and a shoulder peak at 468 nm. GQDs-2 at pH = 13.0 also showed similar PL spectrum splitting into two sharp peaks at 440 and $466 \mathrm{~nm}$, and a shoulder peak at $497 \mathrm{~nm}$. After a detailed correlation of structural characterizations (Figure 2d,f, which indicated the presence of more epoxy chains and minimum hydroxyl/carboxyl functional groups) with optical characterizations (which indicated negligible/small $\mathrm{pH}$ influence in the PL intensity), we attribute the peak splitting of GQDs-2 to the structural rearrangement of graphene induced by chemical functionalities.(36) This speculation is also in agreement with our observation of similar excitation spectra for GQDs-2 corresponding to different PL emissions regardless of the $\mathrm{pH}$ of the medium (Figures $3 \mathrm{~b}$ and S5). Hence, we assume that excitation of same ground states leads to all observed emissions establishing the role of quantum confinement in the PL of GQDs-2.(37) The optical behavior of GQDs-1 with PL spectrum split was qualitatively similar to that of GQDs2. But a slight red shift of the PL emission at 425 and $444 \mathrm{~nm}$ was observed (Figure $4 \mathrm{a}$ ) indicating again the role of quantum confinement effect. Additional evidence for quantum confinement playing a major role in the PL of GQDs was drawn from Tauc plot (Figure 4b). The optical band gaps observed for GQDs-1 and GQDs-2 were 3.18 and $3.41 \mathrm{eV}$, respectively. The increase in band gap with decreasing sizes seen in GQDs-1 ( $6 \mathrm{~nm})$ and GQDs-2 $(\sim 3 \mathrm{~nm})$ reveals quantum confinement effects as the main reason for PL of GQDs rather than the functionalized edge sites.(38) 

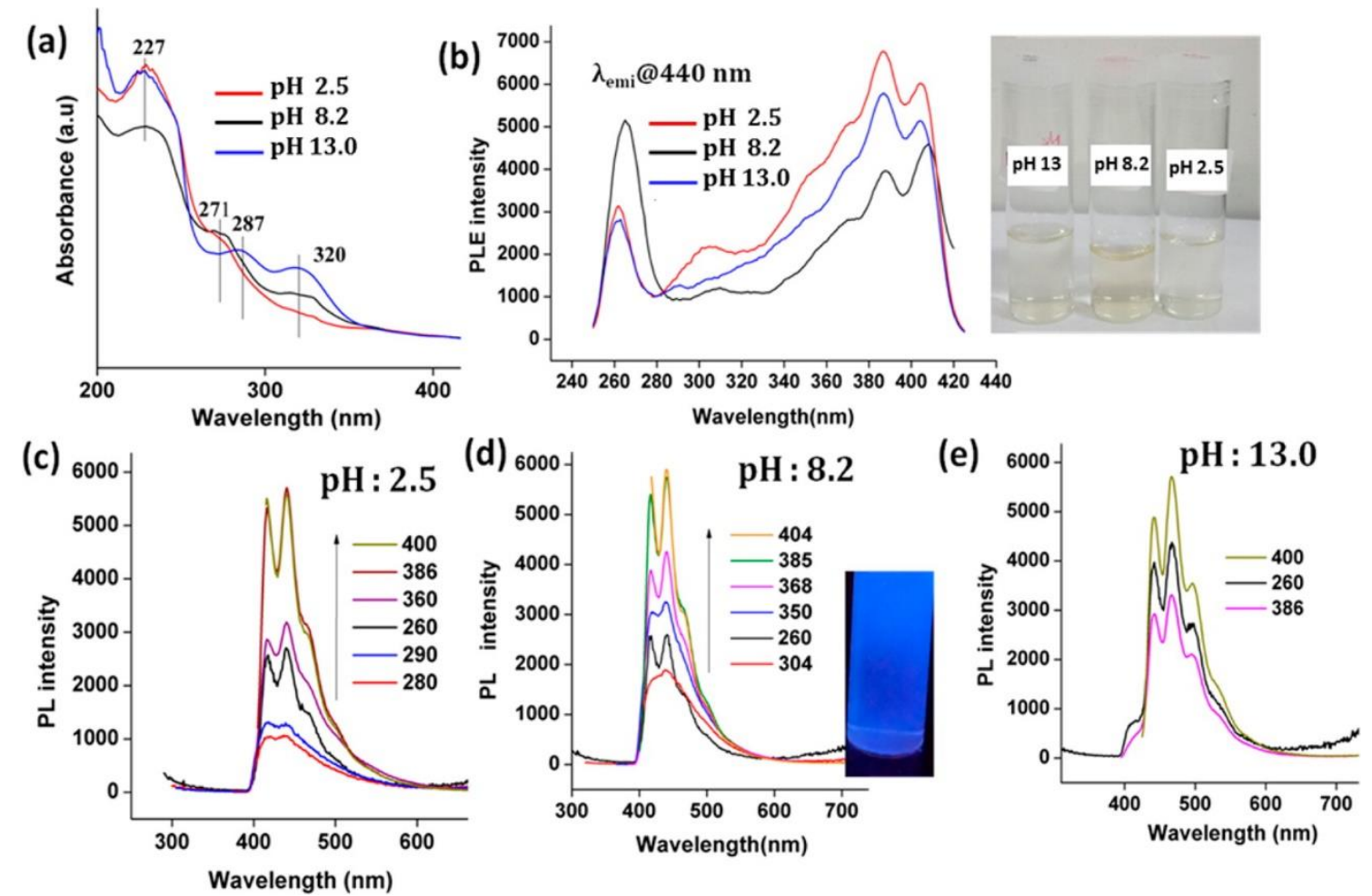

Figure 3. Optical characterization of GQDs-2 at different solution pH: (a) UV-visible absorption spectra. (b) PL-excitation spectra and the optical images (on the right) of GQDs-2 at different $p H$. PL emission spectra at (c) $p H$ 2.5, (d) $p H$ 8.2, and (e) $\mathrm{pH} 13.0$ for different excitation wavelengths. Inset of (d) is the optical image of GQDs-2 excited by UV lamp at 365 $n m$.
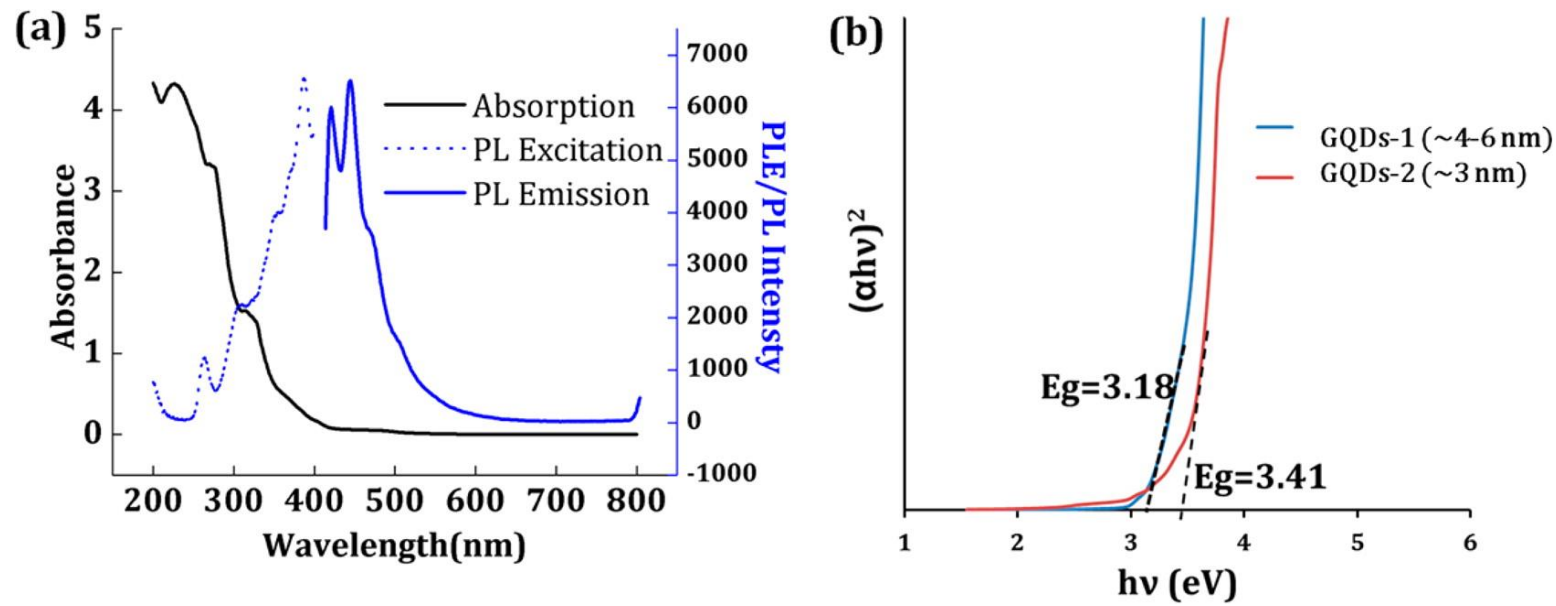

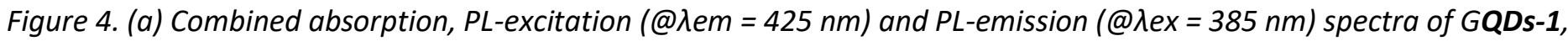
(b) Tauc plots for GQDs-1 and GQDs-2, which have lateral size of 4-6 and $3 \mathrm{~nm}$, respectively.

We have done a comparison experiment with natural graphite flakes and supercritical water by repeating the same experimental procedure, that we used for anthracite coal. The recovered product contained large amount of graphite flakes with slight degree of exfoliation (Figure S6a,b). After centrifugation, the recovered top portion of the supernatant showed bright blue fluorescence. The HRTEM showed crystalline GQDs (Figure S6c-f). However, the product yield for GQDs was calculated to be $<4 \mathrm{wt} \%$. This is because the larger and ordered graphite flakes require strong oxidizing conditions (such as $\mathrm{HNO}_{3}, \mathrm{H}_{2} \mathrm{SO}_{4}, \mathrm{KMnO}_{4}$, etc.) and shearing effect through ultrasonication to effectively cut down the carbon lattice. The anthracite, on the other hand, could not 
withstand such strong oxidizing conditions, if applied, and would end up destroying both aromatic and aliphatic contents. Thus the anthracite requires milder and controllable oxidizing conditions as that of $\mathrm{scH}_{2} \mathrm{O}$. Also of note is that the highly diffusive nature of $\mathrm{scH}_{2} \mathrm{O}$ combined with the shearing effect (from stirring) helped in the exfoliation of GQDs, and thus results in single layer GQDs-2.

Further, we investigated the effect of the reducing supercritical media on coal. The $\mathrm{scH}_{2} \mathrm{O}$ in the previous experiments was replaced with scEtOH (solvent grade, 95\%) to mimic a reducing environment. The scEtOH at $250{ }^{\circ} \mathrm{C}$ is characterized by pronounced hydrogen-bond acidity and weak basicity.(39) For this reason, we can expect less oxidation of coal-carbon lattice with scEtOH. In addition, scEtOH has been proven to exfoliate graphite and well researched for reducing graphene oxide.(40-44) As opposed to $\mathrm{scH}_{2} \mathrm{O}$, the scEtOH treatment of anthracite coal at a temperature of $250{ }^{\circ} \mathrm{C}$ and a pressure of $20 \mathrm{MPa}$ for $60 \mathrm{~min}$ resulted in dark brown suspension with a low intensity broad fluorescence emission in the range 520-660 nm (Figure S7a,b). After centrifugation-redispersion procedures (see the Experimental Section for details), a precipitate was recovered. High aspect ratio nanostructures of ribbon-like morphology (GRs) were found in high density when this precipitate was analyzed by HRTEM (Figure 5a,b) and AFM (Figure 5c,d). We note that along with ribbon-like morphology, some uncut/partially etched sheets and small particles were also seen which remained suspended in ethanol without precipitating out (Figure S8). We assume that in our experiment the less oxidized structures were precipitated during repeated centrifugation-redispersion procedures, while the heavily oxidized nanostructures still remained in the supernatant, which were responsible for the slight fluorescence (Figure S7a,b). The recovered ribbon-like structures were not fluorescent and found with wide range of aspect ratio, i.e, 200-800 nm in length and 20-60 nm in width with some degree of aggregation (Figure 5a,b). The selected area diffraction pattern (inset in Figure 5a) showed the bright main spots arranged in a hexagonal pattern and the diffraction intensity of (110) is higher than $(210)$ as expected from graphene. $(45,46)$ The product yield of recovered GRs is 6.4 wt \%, which, considering uncertainties, is comparable with that of sonochemical cutting of graphene sheets ( 5 wt \%).(16) Note that oxidative unzipping of CNT, although reported to be resulting in higher yield, has the disadvantage of obtaining GRs with higher degree of oxidation, and thus requires heat treatment at $>2000{ }^{\circ} \mathrm{C}$ to restore the electronic properties.(47) The Raman spectrum (Figure 5e) further demonstrated the graphitic nature of GRs with a well-defined D $(1352 \mathrm{~nm}), \mathrm{G}(1565 \mathrm{~nm})$, and $2 \mathrm{D}(2698 \mathrm{~nm})$ peaks. The calculated $I_{\mathrm{D}} / I_{\mathrm{G}}$ ratio varied from 0.91 to 0.2 in Raman spectra obtained from different spots in the deposited sample on a Si substrate (Figure 5e and Figure S9), which is indicative of breakage of symmetry to an extent either through edges and/or defects introduced by the presence of oxygen groups. $(15,16)$ Most of the $I_{\mathrm{D}} / I_{\mathrm{G}}$ values calculated for different spots in the sample were between 0.2 and 0.45 , and occasionally high $I_{\mathrm{D}} / I_{\mathrm{G}}$ value of 0.91 was observed, which were still less than those for GRs synthesized through sonochemical cutting of graphene sheets, CNT unzipping, or CVD growth $\left(I_{\mathrm{D}} / I_{\mathrm{G}}>1.2\right) .(15,16,47)$ The high-resolution $\mathrm{C}$ 1s spectrum from XPS measurements gave Csp ${ }^{2}(284.5$ $\mathrm{eV})$ as major fraction with $\mathrm{Csp}^{3}(285.3 \mathrm{eV})$ and $\mathrm{C}-\mathrm{CO}(286.3 \mathrm{eV})$ as minor fractions (Figure 5f), which was consistent with the Raman data that showed evidence of graphenic structure. 

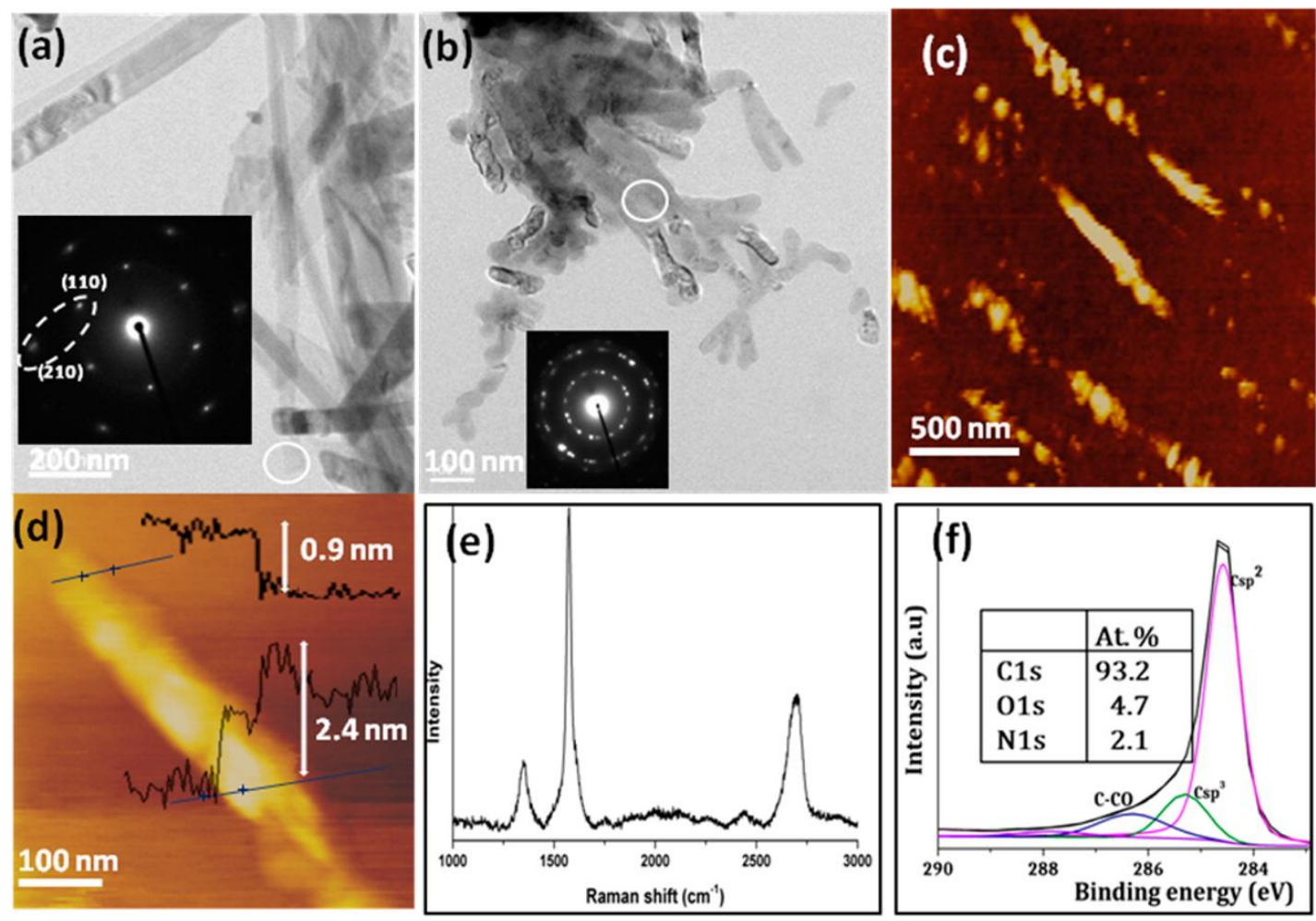

Figure 5. ( $a$ and $b$ ) TEM images of GRs with different aspect ratios. Inset is SAED patterns of selected area indicated by white circles. The two spots within white circle in SAED pattern (inset in a) are (0110) and (1210) planes and are labeled

using Miller-Bravais indices (hkil), (c) AFM image of GRs spin coated on a Si/SiO ${ }_{2}$ substrate. The GRs sample was ultrasonicated in ethanol for 10 min to disperse the aggregated GRs and immediately spin coated. (d) AFM image of an individual GR. Height profiles are given in inset, which indicates layer thickness in the range of 0.9-2.4 nm, confirming few layer nature of GR. (e) Raman spectrum and (f) high-resolution C 1s spectrum of GRs. Inset is atomic percentage information obtained from XPS survey.

Detailed investigation on experimental parameters indicated that besides the temperature and pressure conditions, factors such as solvent purity, starting material, stirring effect, and treatment time have a definite role on the yield and morphology of resulting products. For instance, in the case where there was no stirring, the end products were predominantly large flakes. Similarly, when graphite flakes were used instead of anthracite coal at a temperature of $300{ }^{\circ} \mathrm{C}$ for $1 \mathrm{~h}$, we obtained a mixture of exfoliated and unexfoliated graphite flakes and trace amount of GQDs. On the other hand, if ethanol/water mixtures were used with anthracite coal at a temperature of $300{ }^{\circ} \mathrm{C}$ for $1 \mathrm{~h}$, the product predominantly consisted of blue emissive GQDs and small carbon fragments with trace amount of large flakes. The size and emission color could be controlled by difference in the concentration of anthracite, volume ratio of ethanol to water, and treatment time, etc. (Figure S10). On the other hand, if absolute ethanol (99.8\% purity) was used, predominating product was large flakes similar to the starting anthracite. We have noticed that water, even in trace amount under high temperature-pressure conditions, initiates the cutting of carbon sheets due to its mild oxidizing nature. Li et al. reported that low level oxidation induces line defects (fault lines/cracks) in graphite by cooperative alignment of defects especially by the epoxy groups.(48) A following unzipping process triggered by ultrasonication, thermal and/or hydrothermal exfoliation resulted in serial breakage of $\mathrm{C}-\mathrm{C}$ bonds in a linear mode. The width of the ribbon and edge morphology are generally correlated to the distance between two adjacent line faults and the direction of line faults, respectively.(16) In addition, heteroatoms such as nitrogen present in the carbon lattice are regarded as selective unzipping triggering sites for chemical/electrochemical unzipping of CNT. $(49,50)$ In the HRTEM analysis of as obtained GRs, parallel regular 
morphology was rarely observed; most of the ribbons were seen with irregular edges. It is noteworthy that our scEtOH experiments with graphite as precursor did not give GRs. Similarly, experiments with anthracite coal, but without stirring provided only trace amount of GRs. Considering that the graphite has a quasi-perfect crystalline carbon lattice without any defects and anthracite coal contains considerable oxygen and nitrogen content (Figure S2), we could attribute a combination of factors such as exfoliation effect of supercritical fluids combined with the shearing effect of the stirrer, intrinsic or situational line defects in the anthracite coal, and the heteroatom dopants for the morphology and yield of resulting products. Even though Raman and XPS analysis indicated the graphitic nature of ribbons, a continuous nanometer scale graphene structure is rather unlikely from coal. The detailed HRTEM analysis (Figure 6) indicated a number of randomly arranged different sized crystalline domains inside the ribbon structure. Note that HRTEM provided no evidence of a continuous graphene structure; thus, crystalline domains linked by aliphatic carbon chain may be possibly inferred. Significantly, Kim et al. proposed that scEtOH produces $\alpha$-hydrogen and hydroxyl group which attack the carbon in the epoxy ring and a subsequent proton addition restores the $\pi$ conjugation by forming $\mathrm{CH}_{2}=\mathrm{CH}_{2}$ molecule. $(42,43)$ In another significant work by Stride et al., gram scale graphene was synthesized using just ethanol and sodium in solvothermal conditions.(51) Under the conditions of closed reactor with heated and pressurized alcohol, ethoxide-ethanol clatherate may formed and trapped ethanol acted as ignition point for the nucleation of sheet, the popcorn effect as called by the authors. The XPS analysis of precursor anthracite coal revealed considerable amount of sodium impurity, and a detailed HRTEM analysis of resulting suspension also revealed agglomerated sheets in trace amount with a tendency to coalesce, in accordance with those of Stride et al. (Figure S11).(51) However, these sheets remained suspended in ethanol and were not recovered as precipitate. This may be due to their highly defective nature. The reason for GRs to be precipitated out dominatingly during centrifugationredispersion procedure can only be reasoned as the absence of many oxygen functionalities which in fact is justified by their aggregated nature as revealed in HRTEM images (Figure 5a,b). There have been a handful of reports on solvothermal graphitization effect in the presence of reductant which led to the synthesis of carbon nanosheets with ordered/disordered graphitic structure.(52-54) In the light of these previous studies, our experimental results and also the graphitic nature of the obtained GRs, we may not disregard the possibility of graphitization contribution from scEtOH. 


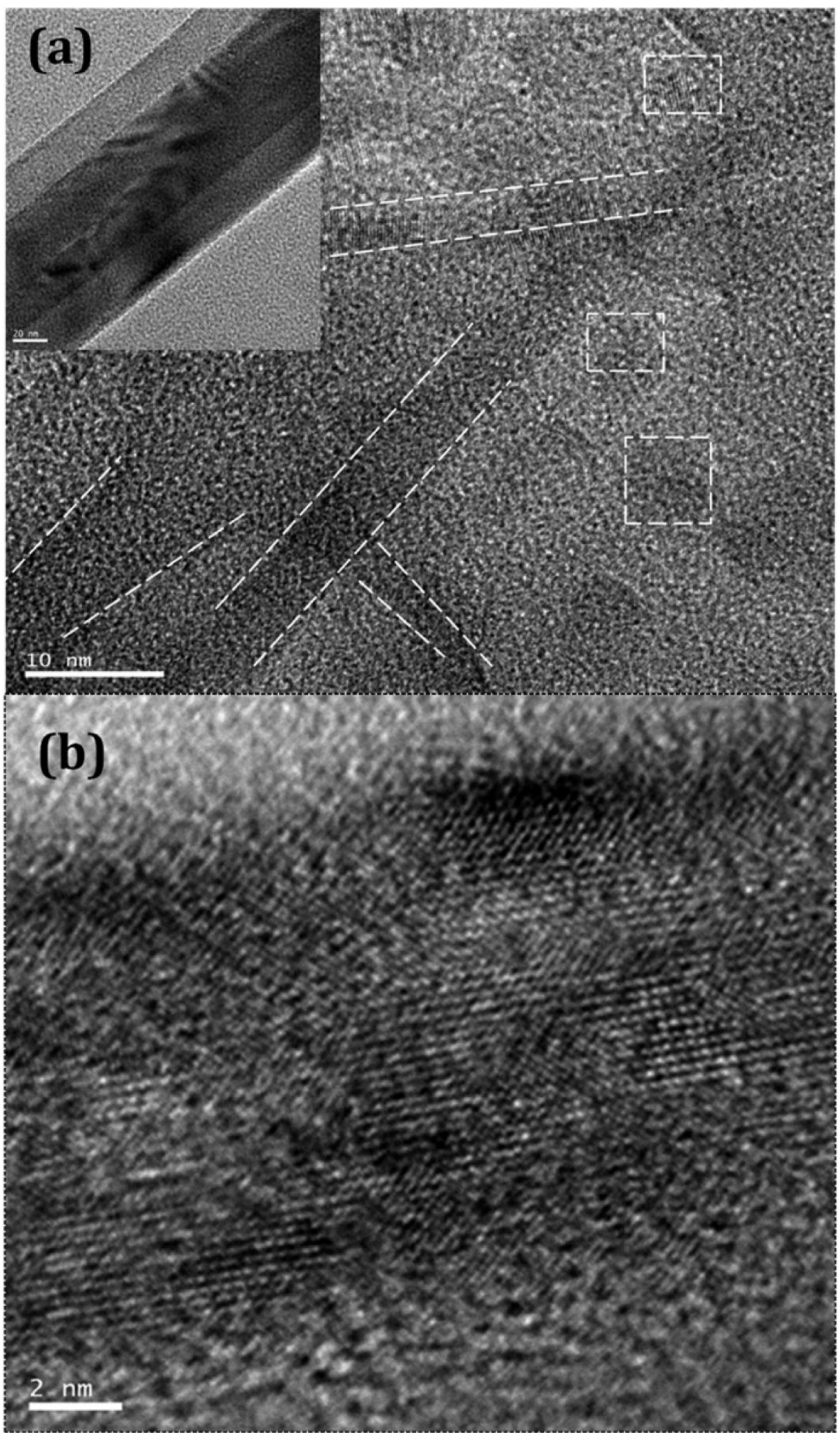

Figure 6. HRTEM images of GR at different magnifications: (a) inset (scale bar $20 \mathrm{~nm}$ ) is an individual GR which is magnified to get the images in (a) and (b). Randomly oriented noncontinuous crystalline domains of different sizes (scale bar $10 \mathrm{~nm}$ ) with graphene fringes are highlighted in (a). (b) At high-magnifications (scale bar $2 \mathrm{~nm}$ ), graphene lattice fringes can be discerned.

In the light of the above discussion, we infer more than one factor to determine the cutting down of coal into graphenic particles of different sizes and aspect ratios. First, the high diffusive nature of supercritical fluids, regardless of their chemical composition, results in exfoliation of the coal. Second, the intrinsic heteroatom doped and disordered crystal structure of coal when combined with the shearing effect from stirring under confined high 
temperature and pressure of reactor conditions cut down the large sheets into small fragments. During this scission and exfoliation process, the extent of oxidizing nature of supercritical fluids determines the size and aspect ratio of the obtained graphenic materials. The oxidizing nature of supercritical water causes concomitant hydropyrolysis reaction which leads to complete depolymerization of coal sheets. This phenomenon results in small crystalline GQDs with small aspect ratio. Also, worthy of note is the fact that increasing the duration of supercritical reaction decreases the number of layers, lateral size, and aspect ratio of obtained GQDs. Decrease of aspect ratio can be understood by considering that anisotropic, ribbon shape particles are more likely cut perpendicular to their main axis, resulting in two smaller particles with lower aspect ratio. Cutting perpendicular to the main axis is more likely to arise because of the small length to cut, and because of shear-induced frictional forces are greater along the main axis, in analogy with polymers or rod-like particles.(55-57) Supercritical ethanol has a more pronounced hydrogen bond acidity and weaker basicity than supercritical water. It seems that supercritical ethanol causes cutting of coal through its line defects and heteroatom doped sites. The scission efficiency being weaker than that of supercritical water, the process results in higher aspect ratio graphenic materials with predominantly ribbon-like morphology of few layers. In addition, the reducing nature of supercritical ethanol presumably helps in the graphitization of GRs, which can explain the observed better electrical conductivity. On the other hand, quantum confinement effects and structural rearrangements due to oxygen functionalization together contribute to the optical properties of GQDs.

Further, potential applications for our obtained GQDs-2 and GRs were investigated. The monodisperse GQDs-2 obtained in water without any stabilizing agents helped them valuable for bioimaging applications. GQDs-2 showed an excellent quantum yield of $28 \%$ measured against quinine sulfate (QS) standard (Figure S12a). Such a high quantum yield is exceptional and cannot be recorded in GQDs without surface passivation with polymers.(9-13) However, it should be noted that GQDs derived from chemically reduced GO after oxidation in concentrated $\mathrm{H}_{2} \mathrm{SO}_{4}$ and $\mathrm{HNO}_{3}$ and an alkaline-hydrothermal deoxidization treatment have been reported to show a maximum quantum yield of 7.5\%.(14) This study indeed gave us an indication that selective oxidation induced cutting has a direct correlation to enhance quantum yield. Our selection of coal as a precursor, which has a disordered structure compared to graphite, helped us to overcome the need for many oxidation-reduction steps, as in the case of above mentioned study. We could attribute the high quantum yield of GQDs-2 to its homogeneous size distribution, and its being the single layer with less defective crystalline lattice. Also GQDs2 showed excellent photostability which is comparable to that of quinine sulfate, and much higher than that of CdSe semiconductor QDs (Figure 7a). Such extended stabilities are not associated with surface passivated quantum dots due to the high incidence of optical degradation in the surface functionalities. This in fact rules out the possibility of some surface adsorbed organics on the GQDs-2, as a reason for its high quantum yield. High contrast bright cell imaging was possible with our obtained GQDs-2. The validation of the potential of the GQDs2 is shown in Figure 7b, where the GQDs-2 have been internalized by HeLa cells into the cytoplasm. The morphology of the cells with phase contrast of nucleus surrounded by blue GQDs-2 can be clearly visualized. The cell viability studies were performed using different concentrations of as prepared GQDs-2 (without any 
purification) in $10 \%$ serum containing media. The Alamar Blue assay indicated no significant toxicity up to the concentration of $40 \mu \mathrm{g} / \mathrm{mL}$, and $<10 \%$ toxicity up to $100 \mu \mathrm{g} / \mathrm{mL}$ for an incubation time of $24 \mathrm{~h}$ (Figure $7 \mathrm{c}$ ).

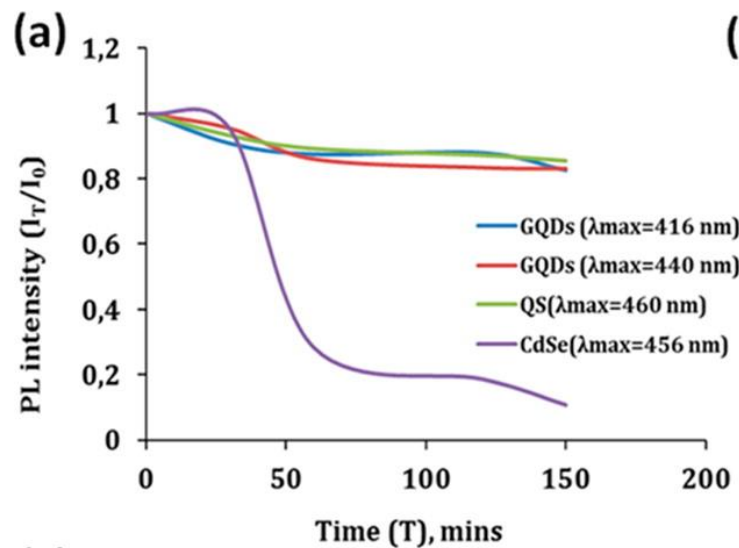

(b)
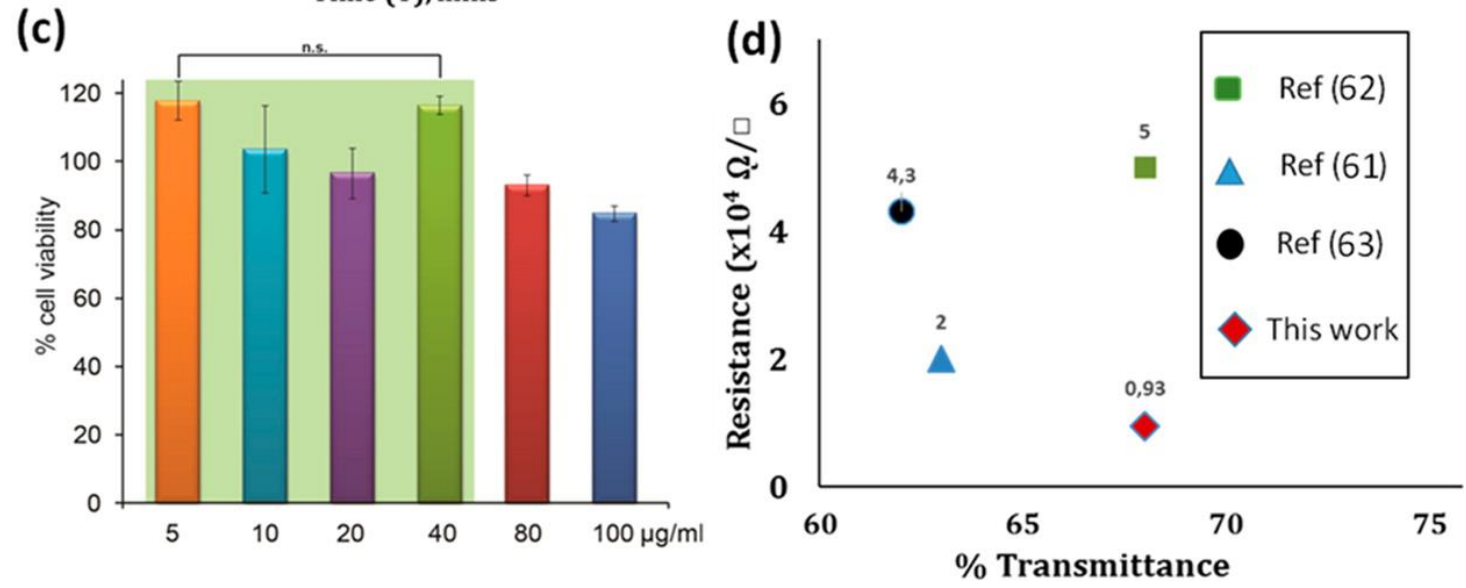

Figure 7. (a) Photostability comparison of GQDs-2 with quinine sulfate and CdSe quantum dots prepared in our group as previously reported.(64) (b) Confocal bright field fluorescence image of HeLa cells at $404 \mathrm{~nm}$ excitation after $24 \mathrm{~h}$ incubation. (c) Cell viability test for HeLa cells incubated with GQDs for $24 \mathrm{~h}$. As shown, no significant toxicity (n.s) up to

$40 \mathrm{\mu g} / \mathrm{mL}$ (Analysis of variance (ANOVA) $p \geq 0.05$ ). (d) Comparison of surface resistance of GRs film with hydrazine treated and annealed GO films reported in literature which have a comparable transmittance $(62-68 \%$ at $\lambda=550 \mathrm{~nm})$.

The high quantum yield and photostability of GQDs-2 are distinctive advantages over other QDs for bioimaging and optoelectronic applications such as light emitting diodes at a low concentration. On the contrary, a thin film of GRs deposited on a glass slide showed a surface resistance of $9.3 \mathrm{k} \Omega / \mathrm{sq}$ with a transparency of $68.2 \%$ (at $\lambda=$ $550 \mathrm{~nm}$, Figure S12b). Such a low resistance compared to GRs made by other methods such as solution phase/plasma unzipping of carbon nanotubes and selective chemical vapor deposition ( $>1 \mathrm{M} \Omega / \mathrm{sq})$ implies high quality of GRs produced by this method.(15, 47, 58-60) This is further confirmed by a correlation study of transparency and surface resistance of obtained GRs compared to high temperature annealed and hydrazine reduced graphene oxide films (Figure 7d).(61-63) As in the case of other synthetic methods, challenges such as uniform edges and stable suspension demand more systematic study on varying supercritical fluids reaction conditions in the future. These results will open avenues toward potential wider application in electrically conductive composite materials where scalable production is more relevant than edge uniformity. Our proposed supercritical fluid method puts forward a new direction for tailoring the morphology of graphenic materials if 
combined with the right precursor. This study initiates further investigations to fully understand and resolve the reaction mechanism behind the effect of supercritical/solvothermal conditions on carbon materials. Nevertheless, this is the first demonstration of the proof of concept concerning the effect of two common solvents, water and ethanol, on a highly ranked coal (i.e., anthracite coal), when treated in a closed container above the critical point. Future work is focused on surface modification of GQDs and their application in photonics and biomedical science, while optimizing reaction conditions to increase the GRs production yield and its full application in electronic devices.

\section{Conclusion}

In conclusion, we report for the first time the supercritical fluid synthesis of aspect ratio controlled graphenic materials from coal. The morphology and electronic properties of obtained GQDs and GRs are greatly influenced by the supercritical solvent of synthesis. The ability to tailor the size, structure, and the properties of graphenic materials from anthracite coal with an oxidizing or a reducing environment offered by $\mathrm{scH}_{2} \mathrm{O}$ and $\mathrm{scEtOH}$, respectively, is demonstrated. No strong acid treatments, delicate synthetic conditions, long reaction time, sonication, or extensive post treatment purification procedures were required for extracting GQDs and GRs from coal. The obtained GQDs showed high PL quantum yield of $28 \%$ measured against quinine sulfate standard. They displayed good biocompatibility and was readily used to image cancer cells. GRs showed high electrical conductivity $(9.3 \mathrm{k} \Omega / \mathrm{sq})$ for an optical transparency of $68 \%$, which opens up a new direction for coal as a source material for electrically conductive graphenic materials. The supercritical fluid based process is sustainable, versatile, and scalable, thus paving the way to large-scale production of these materials.

\section{Experimental Section}

\section{Synthesis of GQDs}

Sixty milligrams of anthracite (Fisher Scientific, catalogue number S98806) was suspended in $60 \mathrm{~mL}$ of water, and loaded into a batch reactor of total $360 \mathrm{~mL}$ capacity. The stirred vessel reactor (Max: $30 \mathrm{MPa}, 550{ }^{\circ} \mathrm{C}$ ) with an Inconel liner and stirrer $(95 \mathrm{~N} \cdot \mathrm{cm})$ is from Top Industrie (17652000) and equipped with 4 blades with an inclination of $45^{\circ}$ in Inconel). The reactor is heated to $400{ }^{\circ} \mathrm{C}$. The internal pressure of the reactor reached 25 $\mathrm{MPa}$ when temperature of water reached $400{ }^{\circ} \mathrm{C}$. The anthracite was allowed to swell in supercritical water for a maximum contact time of 120 min with constant stirring (200 rpm). The reactor was then cooled down naturally after the reaction was stopped. The sample was initially dialyzed in a dialysis bag (0.5-1 kDa, Spectrum Labs, product number G235063) for 5 days, but we did not observe any effect of purification in the surface characteristics or optical properties of GQDs. All the results shown in this study (including cytotoxicity and bioimaging) are with as prepared GQDs, without any purification steps, but centrifuged once (7000 rpm, $30 \mathrm{~min}$ ) to remove any large flakes if present. For comparison experiments, the procedure was repeated with natural graphite keeping all other conditions the same. 


\section{Synthesis of GRs}

The procedure described above was repeated with $50 \mathrm{~mL}$ of ethanol in a reactor of $80 \mathrm{~mL}$ capacity and heated to $250{ }^{\circ} \mathrm{C}$ and $20 \mathrm{MPa}$ to reach the supercritical conditions. The reactor (Max: $30 \mathrm{MPa}, 250{ }^{\circ} \mathrm{C}$ ) from Autoclave Engineers is equipped with a stirrer consisting of radial flow impeller with 6 blades $(74.6 \mathrm{~N} \cdot \mathrm{cm})$ from Maxon Motor (2260.815-51.216-2). All the components are in stainless steel. After 60 min of contact with a stirring speed of $200 \mathrm{rpm}$, the reactor was rapidly cooled by immersing into the ice cold water. The obtained dark brown suspension was centrifuged and the precipitate was redispersed in fresh ethanol. This process was continued for at least six times. The GRs were finally recovered in powder form by vacuum filtration. The comparison experiment with ethanol-water mixture used the same reactor and experimental conditions. The optical and TEM measurements were done with supernatant of centrifuged sample at $7000 \mathrm{rpm}$ for $60 \mathrm{~min}$.

\section{Bioimaging}

HeLa cells were grown in a cell culture flask using low-glucose Dulbecco's modified Eagle medium supplemented with $10 \%$ fetal bovine serum at $37{ }^{\circ} \mathrm{C}$ in a humidified atmosphere of $5 \% \mathrm{CO}_{2}$. For confocal analysis, HeLa cells were seeded at 200000 cells ( $1 \mathrm{~mL} \mathrm{10 \%} \mathrm{serum} \mathrm{containing} \mathrm{media)} \mathrm{in} \mathrm{the} \mathrm{confocal} \mathrm{dish} 24 \mathrm{~h}$ before the experiment. During the experiment, old media were replaced by $100 \mu \mathrm{g} / \mathrm{mL}$ of the GQDs $(1 \mathrm{~mL})$ in serum-containing media, and the cells were incubated for $24 \mathrm{~h}$. The cells were then washed with PBS three times. Confocal microscopy imaging was performed on a Nikon A1R laser scanning confocal microscope equipped with a Nikon Ti Eclipse microscope and a spectrum detector. The diode lasers were used for illumination with wavelength of $405 \mathrm{~nm}$.

\section{Cytotoxicity Measurements of GQDs}

HeLa cells were seeded at 200000 in $1 \mathrm{~mL}$ per well in 12-well plates $24 \mathrm{~h}$ before the experiment. Cells were washed with PBS buffer and then treated with 6 different concentrations ranging from 5 to $100 \mu \mathrm{g} / \mathrm{mL}$ of GQDs in triplicate. After $24 \mathrm{~h}$ of incubation, the cells were then completely washed off with PBS buffer three times, and $10 \%$ Alamar Blue in serum-containing media was added to each well $(1 \mathrm{~mL})$ and further incubated at $37{ }^{\circ} \mathrm{C}$ for $1 \mathrm{~h}$. Cell viability was then determined by measuring the fluorescence intensity $\left(\lambda_{\mathrm{ex}}=560 \mathrm{~nm}\right.$ and $\left.\lambda_{\mathrm{em}}=590 \mathrm{~nm}\right)$ using a SpectraMax M5 microplate spectrophotometer. Further characterization techniques are given in detail as Supporting Information. 


\section{Associated Content}

The Supporting Information is available free of charge on the ACS Publications website at DOI: 10.1021/acsnano.6b01298.

S1: Characterization techniques. S2: Preparation of thin film of GRs. Figure S1: Representative molecular structure of anthracite coal. Figure S2: Characterization of anthracite coal. Figure S3: (a) FTIR-ATR of anthracite coal, (b) TEM of anthracite coal after ultrasonication in water for 60 min. Figure S4: Supercritical water cutting of anthracite coal into GQDs as a function of time. Figure S5: PL-excitation spectra of GQDs-2 corresponding to different emission wavelengths. Figure S6: Comparison experiment to show the effect of $\mathrm{scH}_{2} \mathrm{O}$ treatment on natural graphite flakes. Figure S7: PL- excitation spectrum of the product obtained after anthracite coal was treated with scEtOH. Figure S8: HRTEM analysis of sample obtained from scEtOH treatment of anthracite coal for 60 min. Figure S9: Raman spectra of as obtained GRs deposited on a Si substrate. Figure S10: Effect of ethanol-water mixture on anthracite coal at $250{ }^{\circ} \mathrm{C}$ and $20 \mathrm{MPa}$. Figure S11: TEM images with different magnifications of a sheet structure obtained after scEtOH treatment of anthracite coal. Figure S12: (a) Quantum Yield (QY) calculation for GQDs-2 with respect to quinine sulfate standard, (b) transmittance\% of GRs film on the surface of glass slide (PDF)

Author Information : corresponding : Philippe Poulin - Centre de Recherche Paul Pascal, CNRS, University of Bordeaux, Pessac 33600, France; Email: poulin@crpp-bordeaux.cnrs.fr / Cyril Aymonier - CNRS, University of Bordeaux, ICMCB, UPR 9048, Pessac 33600, France; Email: cyril.aymonier@icmcb.cnrs.fr

Notes : The authors declare no competing financial interest.

Acknowledgment : S.P.S. is thankful to University of Bordeaux and the IdEx postdoctoral fellowship. This work has received financial support from the French State in the frame of the "Investments for the future" Programme IdEx Bordeaux, reference ANR-10-IDEX-03-02 and from the National Institutes of Health (GM077173).

\section{References}

1. Novoselov, K. S.; Geim, A. K.; Morozov, S. V.; Jiang, D.; Zhang, Y.; Dubonos, S. V.; Grigorieva, I. V.; Firsov, A. A. Electric Field Effect in Atomically Thin Carbon Films Science 2004, 306, 666- 669 DOI: 10.1126/science.1102896

2. Shen, J.; Zhu, Y.; Yang, X.; Li, C. Graphene Quantum Dots: Emergent Nanolights for Bioimaging, Sensors, Catalysis and Photovoltaic Devices Chem. Commun. 2012, 48, 3686- 3699 DOI: $10.1039 / \mathrm{c} 2 \mathrm{cc} 00110 \mathrm{a}$

3. Terrones, M.; Botello-Méndez, A. R.; Campos-Delgado, J.; López-Urías, F.; Vega-Cantú, Y. I.; Rodríguez-Macías, F. J.; Elías, A. L.; Muñoz-Sandoval, E.; Cano-Márquez, A. G.; Charlier, J.-C.; Terrones, H. Graphene and Graphite Nanoribbons: Morphology, Properties, Synthesis, Defects and Applications Nano Today 2010, 5, 351-372 DOI: 10.1016/j.nantod.2010.06.010 
4. Bianco, A.; Cheng, H. M.; Enoki, T.; Gogotsi, Y.; Hurt, R. H.; Koratkar, N.; Kyotani, T.; Monthioux, M.; Park, C. R.; Tascon, J. M.; Zhang, J. All in the Graphene Family-A Recommended Nomenclature for Two-Dimensional Carbon Materials Carbon 2013, 65, 1- 6 DOI: 10.1016/j.carbon.2013.08.038

5. Shi, B.; Zhang, L.; Lan, C.; Zhao, J.; Su, Y.; Zhao, S. One-Pot Green Synthesis of Oxygen-Rich Nitrogen-Doped Graphene Quantum Dots and Their Potential Application in Ph-Sensitive Photoluminescence and Detection of Mercury(II) Ions Talanta 2015, 142, 131-139 DOI: 10.1016/j.talanta.2015.04.059

6. Baker, S. N.; Baker, G. A. Luminescent Carbon Nanodots: Emergent Nanolights Angew. Chem., Int. Ed. 2010, 49, 6726- 6744 DOI: 10.1002/anie.200906623

7. Pan, D.; Zhang, J.; Li, Z.; Wu, M. Hydrothermal Route for Cutting Graphene Sheets into BlueLuminescent Graphene Quantum Dots Adv. Mater. 2010, 22, 734- 738 DOI: 10.1002/adma.200902825

8. Feng, L.; Tang, X.-Y.; Zhong, Y.-X.; Liu, Y.-W.; Song, X.-H.; Deng, S.-L.; Xie, S.-Y.; Yan, J.-W.; Zheng, L.-S. Ultra-Bright Alkylated Graphene Quantum Dots Nanoscale 2014, 6, 12635- 12643 DOI: 10.1039/C4NR03506B

9. Prasannan, A.; Imae, T. One-Pot Synthesis of Fluorescent Carbon Dots from Orange Waste Peels Ind. Eng. Chem. Res. 2013, 52, 15673-15678 DOI: 10.1021/ie402421s

10. Li, L.; Wu, G.; Yang, G.; Peng, J.; Zhao, J.; Zhu, J.-J. Focusing on Luminescent Graphene Quantum Dots: Current Status and Future Perspectives Nanoscale 2013, 5, 4015-4039 DOI: 10.1039/c3nr33849e

11. Li, L.-L.; Ji, J.; Fei, R.; Wang, C.-Z.; Lu, Q.; Zhang, J.-R.; Jiang, L.-P.; Zhu, J.-J. A Facile Microwave Avenue to Electrochemiluminescent Two-Color Graphene Quantum Dots Adv. Funct. Mater. 2012, 22, 2971- 2979 DOI: 10.1002/adfm.201200166

12. Zhu, S.; Zhang, J.; Tang, S.; Qiao, C.; Wang, L.; Wang, H.; Liu, X.; Li, B.; Li, Y.; Yu, W.; Wang, X.; Sun, H.; Yang, B. Surface Chemistry Routes to Modulate the Photoluminescence of Graphene Quantum Dots: From Fluorescence Mechanism to Up-Conversion Bioimaging Applications Adv. Funct. Mater. 2012, 22, 4732- 4740 DOI: 10.1002/adfm.201201499

13. Shen, J.; Zhu, Y.; Yang, X.; Zong, J.; Zhang, J.; Li, C. One-Pot Hydrothermal Synthesis of Graphene Quantum Dots Surface-Passivated by Polyethylene Glycol and Their Photoelectric Conversion Under Near-Infrared Light New J. Chem. 2012, 36, 97- 101 DOI: 10.1039/C1NJ20658C

14. Pan, D.; Guo, L.; Zhang, J.; Xi, C.; Xue, Q.; Huang, H.; Li, J.; Zhang, Z.; Yu, W.; Chen, Z.; Li, Z. Cutting sp ${ }^{2}$ Clusters in Graphene Sheets into Colloidal Graphene Quantum Dots with Strong Green Fluorescence J. Mater. Chem. 2012, 22, 3314- 3318 DOI: 10.1039/c2jm16005f

15. An, H.; Lee, W.-G.; Jung, J. Synthesis of Graphene Ribbons Using Selective Chemical Vapor Deposition Curr. Appl. Phys. 2012, 12, 1113- 1117 DOI: 10.1016/j.cap.2012.02.005

16. Wu, Z.-S.; Ren, W.; Gao, L.; Liu, B.; Zhao, J.; Cheng, H.-M. Efficient Synthesis of Graphene Nanoribbons Sonochemically Cut from Graphene Sheets Nano Res. 2010, 3, 16- 22 DOI: 10.1007/s12274-010-1003-7

17. Yang, X.; Dou, X.; Rouhanipour, A.; Zhi, L.; Räder, H. J.; Müllen, K. Two-Dimensional Graphene Nanoribbons J. Am. Chem. Soc. 2008, 130, 4216- 4217 DOI: 10.1021/ja710234t

18. Yu, W. J.; Chae, S. H.; Perello, D.; Lee, S. Y.; Han, G. H.; Yun, M.; Lee, Y. H. Synthesis of EdgeClosed Graphene Ribbons with Enhanced Conductivity ACS Nano 2010, 4, 5480- 5486 DOI: $10.1021 / \mathrm{nn} 101581 \mathrm{k}$

19. Jiao, L.; Wang, X.; Diankov, G.; Wang, H.; Dai, H. Facile Synthesis of High-Quality Graphene Nanoribbons Nat. Nanotechnol. 2010, 5, 321- 325 DOI: 10.1038/nnano.2010.54

20. Skaltsas, T.; Ke, X.; Bittencourt, C.; Tagmatarchis, N. Ultrasonication Induces Oxygenated Species and Defects onto Exfoliated Graphene J. Phys. Chem. C 2013, 117, 23272- 23278 DOI: 10.1021/jp4057048

21. Meyers, R. Coal Structure; Elsevier, 2012.

22. Davidson, R. M. Molecular Structure of Coal Coal Science 1982, 1, 83- 160 DOI: 10.1016/B978-0-12150701-5.50009-7

23. Ye, R.; Xiang, C.; Lin, J.; Peng, Z.; Huang, K.; Yan, Z.; Cook, N. P.; Samuel, E. L. G.; Hwang, C.-C.; Ruan, G.; Ceriotti, G.; Raji, A.-R. O.; Martí, A. a.; Tour, J. M. Coal as an Abundant Source of Graphene Quantum Dots Nat. Commun. 2013, 4, 2943- 2943 DOI: 10.1038/ncomms3943

24. Ye, R.; Peng, Z.; Metzger, A.; Lin, J.; Mann, J. a.; Huang, K.; Xiang, C.; Fan, X.; Samuel, E. L. G.; Alemany, L. B.; Martí, A. a.; Tour, J. M. Bandgap Engineering of Coal-Derived Graphene Quantum Dots ACS Appl. Mater. Interfaces 2015, 7, 7041- 7048 DOI: 10.1021/acsami.5b01419 
25. Dong, Y.; Lin, J.; Chen, Y.; Fu, F.; Chi, Y.; Chen, G. Graphene Quantum Dots, Graphene Oxide, Carbon Quantum Dots and Graphite Nanocrystals in Coals Nanoscale 2014, 6, 7410- 7415 DOI: $10.1039 / \mathrm{c} 4 \mathrm{nr} 01482 \mathrm{k}$

26. Bröll, D.; Kaul, C.; Krämer, A.; Krammer, P.; Richter, T.; Jung, M.; Vogel, H.; Zehner, P. Chemistry in Supercritical Water Angew. Chem., Int. Ed. 1999, 38, 2998- 3014 DOI: 10.1002/(SICI)15213773(19991018)38:20<2998::AID-ANIE2998>3.3.CO;2-C

27. Saisu, M.; Sato, T.; Watanabe, M.; Adschiri, T.; Arai, K. Conversion of Lignin with Supercritical Water-Phenol Mixtures Energy Fuels 2003, 17, 922- 928 DOI: 10.1021/ef0202844

28. Brunner, G. Near and Supercritical Water. Part II: Oxidative Processes J. Supercrit. Fluids 2009, 47, 382- 390 DOI: 10.1016/j.supflu.2008.09.001

29. Brunner, G. Near Critical and Supercritical Water. Part I. Hydrolytic and Hydrothermal Processes J. Supercrit. Fluids 2009, 47, 373-381 DOI: 10.1016/j.supflu.2008.09.002

30. Tomai, T.; Tamura, N.; Honma, I. One-Step Production of Anisotropically Etched Graphene Using Supercritical Water ACS Macro Lett. 2013, 2, 794- 798 DOI: 10.1021/mz400186t

31. Killilea, W. R.; Swallow, K. C.; Hong, G. T. The Fate of Nitrogen in Supercritical-Water Oxidation J. Supercrit. Fluids 1992, 5, 72- 78 DOI: 10.1016/0896-8446(92)90044-K

32. Peng, J.; Gao, W.; Gupta, B. K.; Liu, Z.; Romero-Aburto, R.; Ge, L.; Song, L.; Alemany, L. B.; Zhan, X.; Gao, G.; Vithayathil, S. A.; Kaipparettu, B. A.; Marti, A. A.; Hayashi, T.; Zhu, J.-J.; Ajayan, P. M. Graphene Quantum Dots Derived from Carbon Fibers Nano Lett. 2012, 12, 844- 849 DOI: $10.1021 / \mathrm{nl} 2038979$

33. Sun, Y.; Wang, S.; Li, C.; Luo, P.; Tao, L.; Wei, Y.; Shi, G. Large Scale Preparation of Graphene Quantum Dots from Graphite with Tunable Fluorescence Properties Phys. Chem. Chem. Phys. 2013, 15, 9907- 9913 DOI: 10.1039/c3cp50691f

34. Jin, S. H.; Kim, D. H.; Jun, G. H.; Hong, S. H.; Jeon, S. Tuning the Photoluminescence of Graphene Quantum Dots through the Charge Transfer Effect of Functional Groups ACS Nano 2013, 7, 12391245 DOI: $10.1021 / \mathrm{nn} 304675 \mathrm{~g}$

35. Lee, J.; Kim, K.; Park, W. I.; Kim, B.-H.; Park, J. H.; Kim, T.-H.; Bong, S.; Kim, C.-H.; Chae, G.; Jun, M.; Hwang, Y.; Jung, Y. S.; Jeon, S. Uniform Graphene Quantum Dots Patterned from Self-Assembled Silica Nanodots Nano Lett. 2012, 12, 6078- 6083 DOI: 10.1021/nl302520m

36. Gong, P.; Wang, J.; Sun, W.; Wu, D.; Wang, Z.; Fan, Z.; Wang, H.; Han, X.; Yang, S. Tunable Photoluminescence and Spectrum Split from Fluorinated to Hydroxylated Graphene Nanoscale 2014, 6, 3316- 3324 DOI: 10.1039/c3nr05725a

37. Galande, C.; Mohite, A. D.; Naumov, A. V.; Gao, W.; Ci, L.; Ajayan, A.; Gao, H.; Srivastava, A.; Weisman, R. B.; Ajayan, P. M. Quasi-Molecular Fluorescence from Graphene Oxide Sci. Rep. 2011, 1, 885 DOI: $10.1038 /$ srep00085

38. Park, N.-M.; Choi, C.-J.; Seong, T.-Y.; Park, S.-J. Quantum Confinement in Amorphous Silicon Quantum Dots Embedded in Silicon Nitride Phys. Rev. Lett. 2001, 86, 1355- 1357 DOI: 10.1103/PhysRevLett.86.1355

39. Lu, J.; Boughner, E. C.; Liotta, C. L.; Eckert, C. A. Nearcritical and Supercritical Ethanol as a Benign Solvent: Polarity and Hydrogen-Bonding Fluid Phase Equilib. 2002, 198, 37- 49 DOI: 10.1016/S03783812(01)00754-3

40. Liu, S.; Chen, K.; Fu, Y.; Yu, S.; Bao, Z. Reduced Graphene Oxide Paper by Supercritical Ethanol Treatment and Its Electrochemical Properties Appl. Surf. Sci. 2012, 258, 5299- 5303 DOI: 10.1016/j.apsusc.2012.02.023

41. Kong, C. Y.; Song, W.-L.; Meziani, M. J.; Tackett, K. N., II; Cao, L.; Farr, A. J.; Anderson, A.; Sun, Y.-P. Supercritical Fluid Conversion of Graphene Oxides J. Supercrit. Fluids 2012, 61, 206-211 DOI: 10.1016/j.supflu.2011.09.008

42. Seo, M.; Yoon, D.; Hwang, K. S.; Kang, J. W.; Kim, J. Supercritical Alcohols as Solvents and Reducing Agents for the Synthesis of Reduced Graphene Oxide Carbon 2013, 64, 207- 218 DOI: 10.1016/j.carbon.2013.07.053

43. Nursanto, E.; Nugroho, A.; Hong, S.; Kim, S.; Chung, K. Y.; Kim, J. Facile Synthesis of Reduced Graphene Oxide in Supercritical Alcohols and Its Lithium Storage Capacity Green Chem. 2011, 13, 2714- 2718 DOI: 10.1039/c1gc15678k 
44. Rangappa, D.; Sone, K.; Wang, M.; Gautam, U. K.; Golberg, D.; Itoh, H.; Ichihara, M.; Honma, I. Rapid and Direct Conversion of Graphite Crystals into High-Yielding, Good-Quality Graphene by Supercritical Fluid Exfoliation Chem. - Eur. J. 2010, 16, 6488- 6494 DOI: 10.1002/chem.201000199

45. Kumar, S.; McEvoy, N.; Lutz, T.; Keeley, G. P.; Nicolosi, V.; Murray, C. P.; Blau, W. J.; Duesberg, G. S. Gas Phase Controlled Deposition of High Quality Large-Area Graphene Films Chem. Commun. 2010, 46, 1422- 1424 DOI: 10.1039/b919725g

46. Meyer, J. C.; Geim, A. K.; Katsnelson, M. I.; Novoselov, K. S.; Booth, T. J.; Roth, S. The Structure of Suspended Graphene Sheets Nature 2007, 446, 60- 63 DOI: 10.1038/nature05545

47. Kosynkin, D. V.; Higginbotham, A. L.; Sinitskii, A.; Lomeda, J. R.; Dimiev, A.; Price, B. K.; Tour, J. M. Longitudinal Unzipping of Carbon Nanotubes to Graphene Nanoribbons Nature 2009, 458, 872876 DOI: $10.1038 /$ nature 07872

48. Li, J.; Kudin, K. N.; McAllister, M. J.; Prud'homme, R. K.; Aksay, I. A.; Car, R. Oxygen-Driven Unzipping of Graphitic Materials Phys. Rev. Lett. 2006, 96, 176101-176104 DOI:

10.1103/PhysRevLett.96.176101

49. Cruz-Silva, R.; Morelos-Gómez, A.; Vega-Díaz, S.; Tristán-López, F.; Elias, A. L.; Perea-López, N.; Muramatsu, H.; Hayashi, T.; Fujisawa, K.; Kim, Y. A.; Endo, M.; Terrones, M. Formation of NitrogenDoped Graphene Nanoribbons via Chemical Unzipping ACS Nano 2013, 7, 2192-2204 DOI: $10.1021 / \mathrm{nn} 305179 \mathrm{~b}$

50. Lim, J.; Maiti, U. N.; Kim, N.; Narayan, R.; Lee, W. J.; Choi, D. S.; Oh, Y.; Lee, J.; Lee, G.; Kang, S. H.; Kim, H.; Kim, Y.; Kim, S. O. Dopant-Specific Unzipping of Carbon Nanotubes for Intact Crystalline Graphene Nanostructures Nat. Commun. 2016, 7, 10364 DOI: 10.1038/ncomms10364

51. Choucair, M.; Thordarson, P.; Stride, J. A. Gram-Scale Production of Graphene Based on Solvothermal Synthesis and Sonication Nat. Nanotechnol. 2009, 4, 30- 33 DOI: 10.1038/nnano.2008.365

52. Kuang, Q.; Xie, S. Y.; Jiang, Z. Y.; Zhang, X. H.; Xie, Z. X.; Huang, R. B.; Zheng, L. S. Low Temperature Solvothermal Synthesis of Crumpled Carbon Nanosheets Carbon 2004, 42, 17371741 DOI: 10.1016/j.carbon.2004.03.008

53. Brooks, J. D.; Taylor, G. H. The Formation of Graphitizing Carbons from the Liquid Phase Carbon 1965, 3, 185- 193 DOI: 10.1016/0008-6223(65)90047-3

54. Shen, J. M.; Feng, Y. T. Formation of Flower-Like Carbon Nanosheet Aggregations and Their Electrochemical Application J. Phys. Chem. C 2008, 112, 13114- 13120 DOI: 10.1021/jp802285c

55. Kuijpers, M. W. A.; Iedema, P. D.; Kemmere, M. F.; Keurentjes, J. T. F. The Mechanism of CavitationInduced Polymer Scission; Experimental and Computational Verification Polymer 2004, 45, 64616467 DOI: 10.1016/j.polymer.2004.06.051

56. Lucas, A.; Zakri, C.; Maugey, M.; Pasquali, M.; van der Schoot, P.; Poulin, P. Kinetics of Nanotube and Microfiber Scission under Sonication J. Phys. Chem. C 2009, 113, 20599- 20605 DOI: 10.1021/jp906296y

57. Odell, J. A.; Keller, A.; Rabin, Y. Flow-Induced Scission of Isolated Macromolecules J. Chem. Phys. 1988, 88, 4022- 4028 DOI: 10.1063/1.453855

58. Zhang, Z.; Sun, Z.; Yao, J.; Kosynkin, D. V.; Tour, J. M. Transforming Carbon Nanotube Devices into Nanoribbon Devices J. Am. Chem. Soc. 2009, 131, 13460- 13463 DOI: 10.1021/ja9045923

59. Jiao, L.; Zhang, L.; Wang, X.; Diankov, G.; Dai, H. Narrow Graphene Nanoribbons from Carbon Nanotubes Nature 2009, 458, 877- 880 DOI: 10.1038/nature07919

60. Wei, D.; Liu, Y.; Zhang, H.; Huang, L.; Wu, B.; Chen, J.; Yu, G. Scalable Synthesis of Few-Layer Graphene Ribbons with Controlled Morphologies by a Template Method and Their Applications in Nanoelectromechanical Switches J. Am. Chem. Soc. 2009, 131, 11147- 1115 DOI: 10.1021/ja903092k

61. Wu, J.; Becerril, H. A.; Bao, Z.; Liu, Z.; Chen, Y.; Peumans, P. Organic Solar Cells with SolutionProcessed Graphene Transparent Electrodes Appl. Phys. Lett. 2008, 92, 263302-263308 DOI: $10.1063 / 1.2924771$

62. Becerril, H. A.; Mao, J.; Liu, Z.; Stoltenberg, R. M.; Bao, Z.; Chen, Y. Evaluation of Solution-Processed Reduced Graphene Oxide Films as Transparent Conductors ACS Nano 2008, 2, 463- 470 DOI: $10.1021 / \mathrm{nn} 700375 \mathrm{n}$

63. Eda, G.; Fanchini, G.; Chhowalla, M. Large-Area Ultrathin Films of Reduced Graphene Oxide as a Transparent and Flexible Electronic Material Nat. Nanotechnol. 2008, 3, 270- 274 DOI: 10.1038/nnano.2008.83 
64. Chakrabarty, A.; Marre, S.; Landis, R. F.; Rotello, V. M.; Maitra, U.; Del Guerzo, A.; Aymonier, C. Continuous Synthesis of High Quality CdSe Quantum Dots in Supercritical Fluids J. Mater. Chem. C 2015, 3, 7561-7566 DOI: 10.1039/C5TC01115A 